\title{
Notes on the vocalizations of Blue-and-yellow Tanager (Thraupis
} bonariensis)

Peter Boesman

In the following we briefly analyze and compare voice of the different races of Blue-andyellow Tanager (Thraupis bonariensis). We also try to quantify the extent of any vocal differences using the criteria proposed by Tobias et al. (2010), as a support for taxonomic review. We have made use of sound recordings available on-line from Xeno Canto (XC).

Our main interest is to compare green-backed northern race darwinii with other races. A comparison, illustrated with sonograms:

$\underline{\text { darwinii }}$

Ecuador
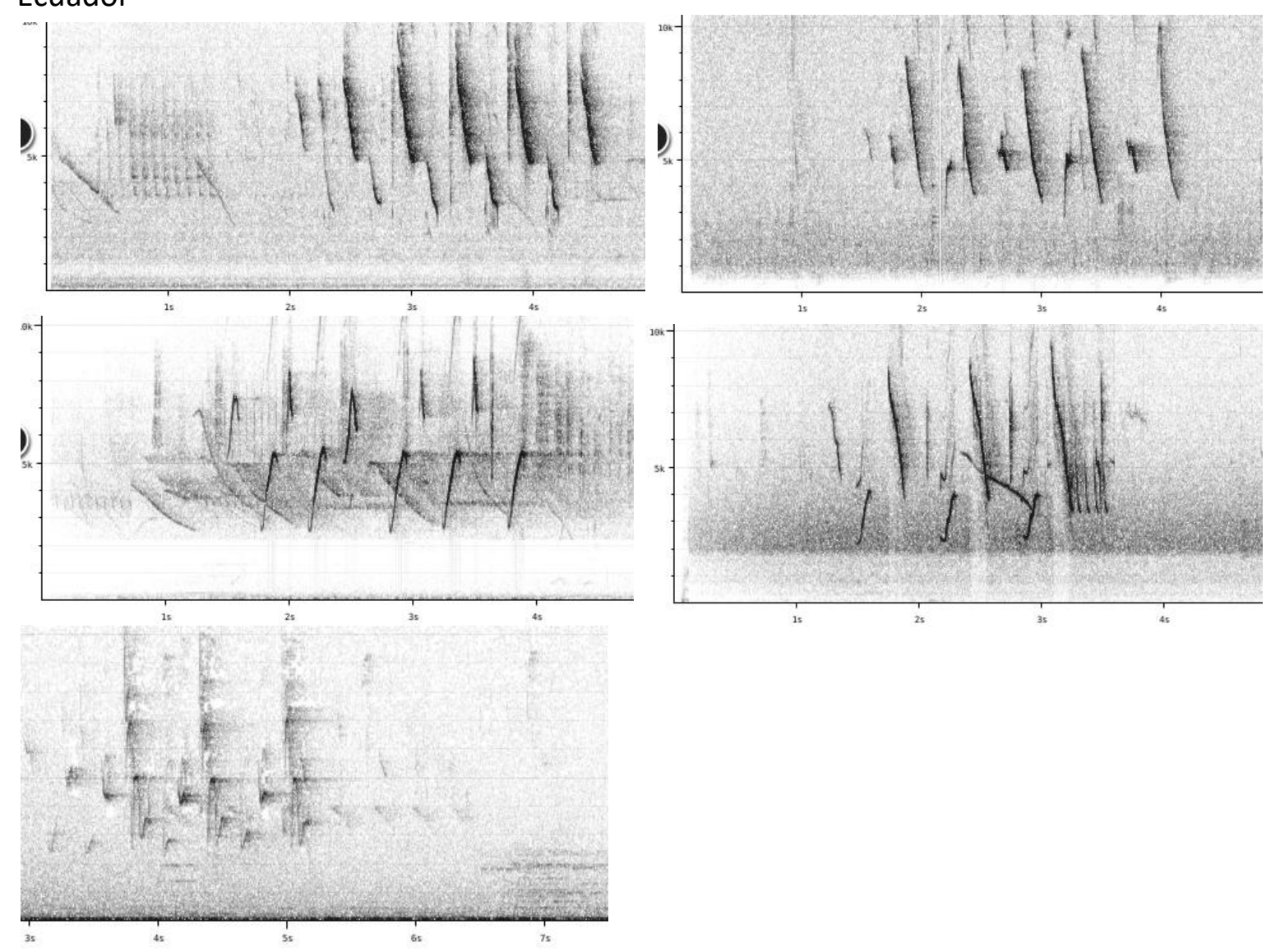
HANDBOOK OF THE

BIRDSPFIE WORLD ORNITHOLOGICAL NOTES
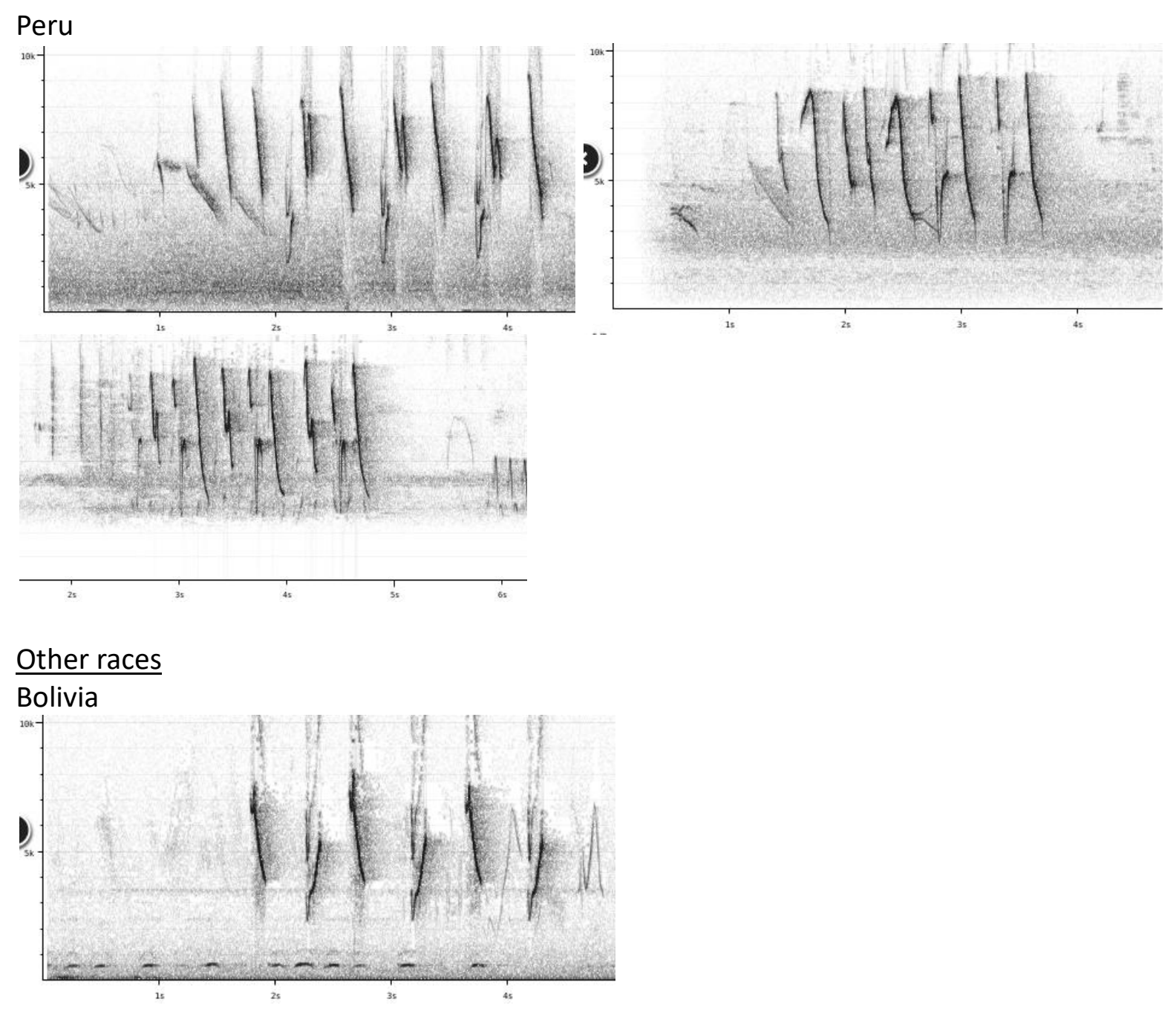

Argentina

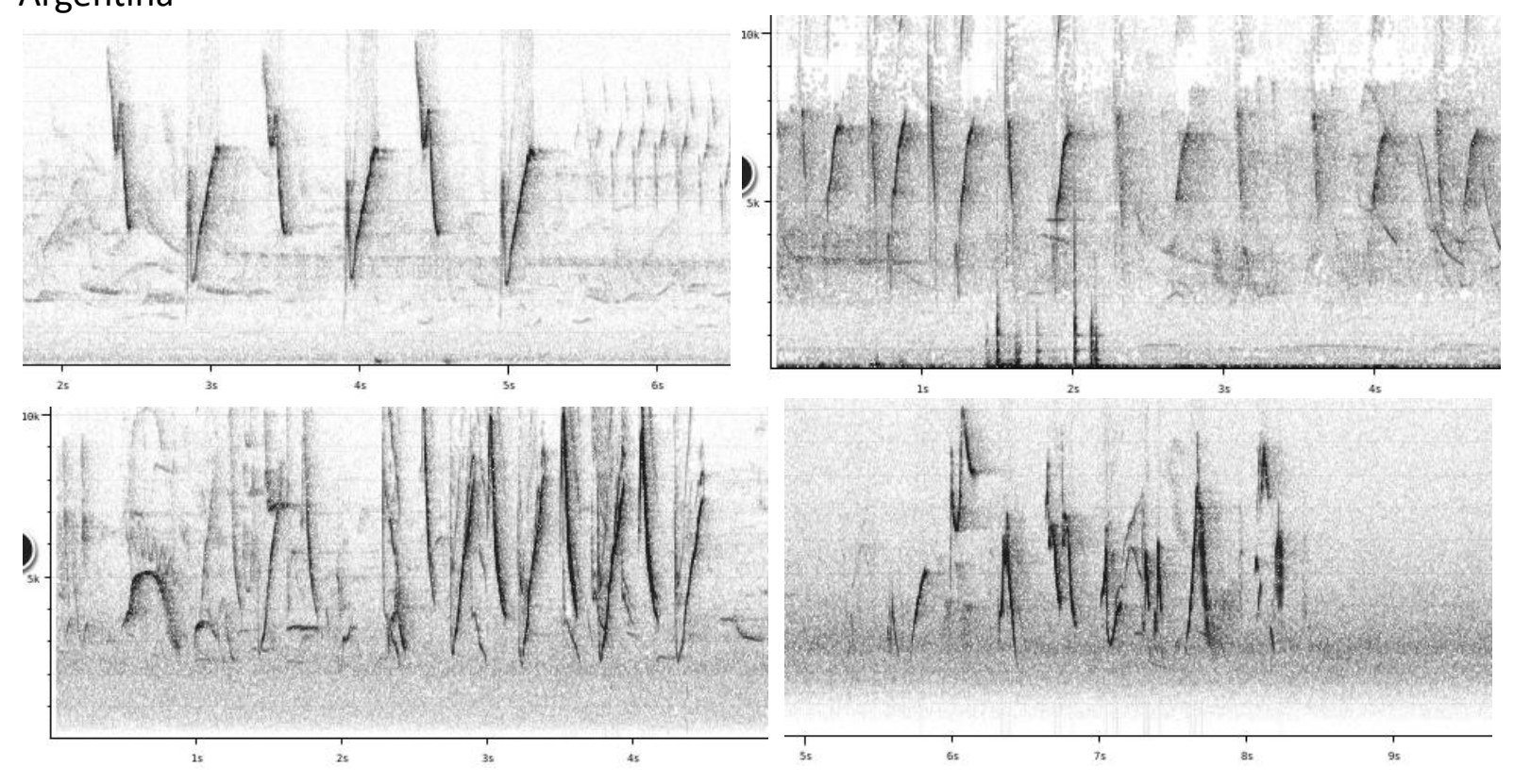



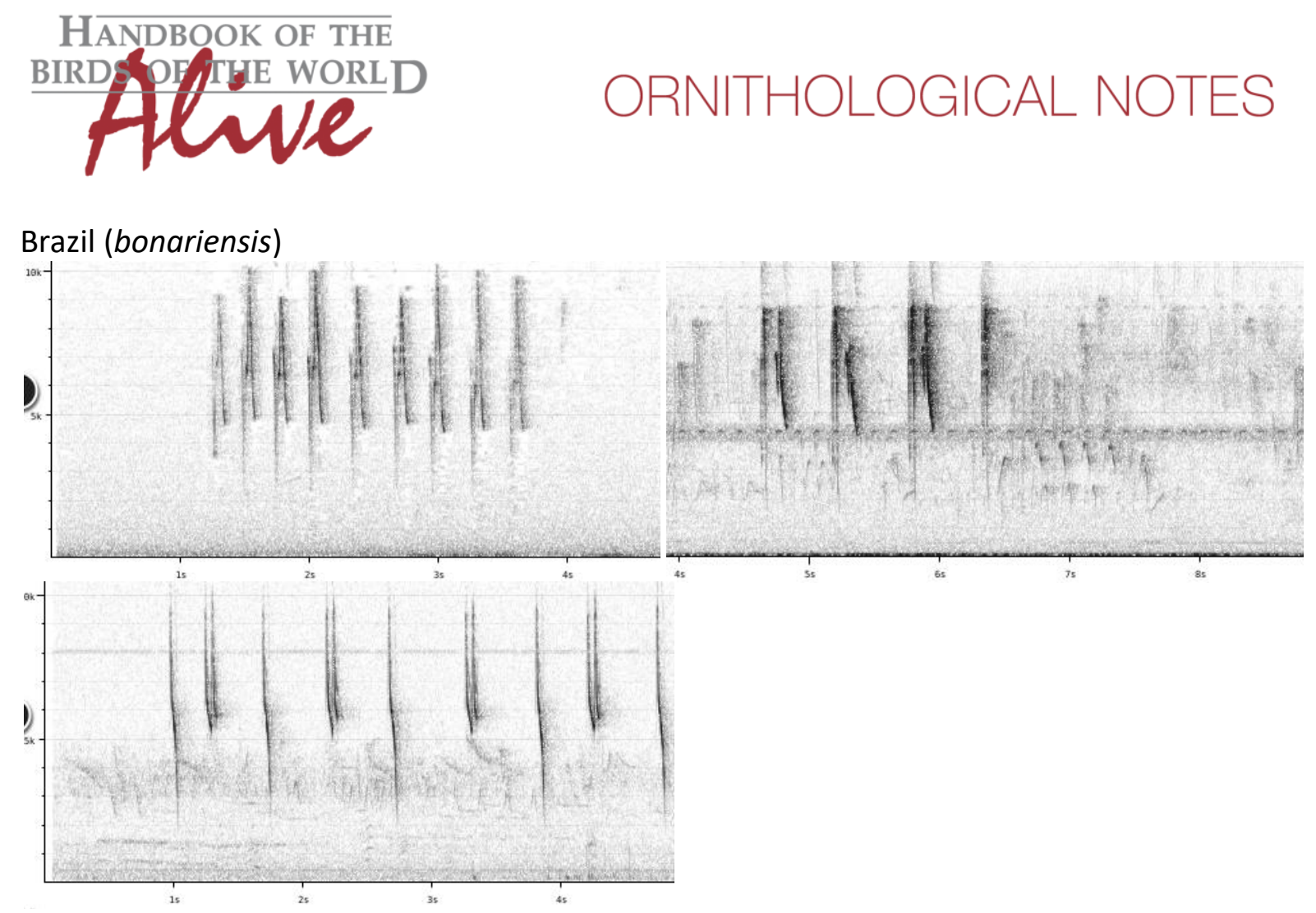

Song is quite variable, typically a sub-phrase of 2-3 notes repeated several times, sometimes with slight changes. Often alternating downslurred and (lower-pitched) upslurred notes.

Pace also quite variable. Some song (?) phrases lack the typical regular pattern. Overall, song is quite similar over entire range, but:

darwini can be recognized from all other races by the presence of lower-pitched notes, which reach a max. frequency of $c 3.5-6 \mathrm{kHz}(v s c 6-8 \mathrm{kHz}$ in southern races, even more in bonariensis) and cover a much smaller frequency range (c $2-3 \mathrm{kHz}$ vs $3-6 \mathrm{kHz})$ (score 1+1=2). bonariensis apparently lacks a clear pattern of alternating downslurred and upslurred notes, notes are higher-pitched and less melodious.

We can thus conclude that race darwini can be identified by alternating high-pitched and low-pitched notes, races composita/schulzei has alternating upslurred and downslurred notes, while race bonariensis has high-pitched repeated notes but lacks upslurred notes.

This note was finalized on 5th July 2016, using sound recordings available on-line at that moment. We would like to thank in particular the many sound recordists who placed their recordings for this species on XC.

\section{References}

Tobias, J.A., Seddon, N., Spottiswoode, C.N., Pilgrim, J.D., Fishpool, L.D.C. \& Collar, N.J. (2010). Quantitative criteria for species delimitation. Ibis 152(4): 724-746.

\section{Recommended citation}

Boesman, P. (2016). Notes on the vocalizations of Blue-and-yellow Tanager (Thraupis bonariensis). HBW Alive Ornithological Note 402. In: Handbook of the Birds of the World Alive. Lynx Edicions, Barcelona. (retrieved from http://www.hbw.com/node/1253796 on 2 December 2016). 